\title{
KEBERAGAMAAN MAHASISWA DI PERGURUAN TINGGI WILAYAH MINORITAS MUSLIM
}

\author{
Ismail Suardi Wekke, Asep Hermawanto, Muhammad Ashrori \\ Sekolah Tinggi Agama Islam Negeri (STAIN) Sorong \\ Email: iswekke@gmail.com
}

\begin{abstract}
Higher education is a part of society, therefore Islamic university is also as part of their environment. This article identifies how Islamic higher education accelerates their institution to provide students opportunity to learn religious subject outside classroom so that they have enough time to learn in non-formal situation. The data was collected through brief in-depth interview and non-participant observation. Islamic State College of Sorong is the main source of data. Focus group discussion was applied as the technique to verify data for triangulation. This article discusses two main activities, celebration of Prophet Muhammad and the moment of first time reciting al Quran. Finally, this article concludes that the institution in higher learning activity play two roles, the university itself and the same time they are the religious body of the society.

Pendidikan Tinggi merupakan bagian dari masyarakat, untuk itu universitas Islam merupakan bagian dari lingkungan yang mereka diami. Artikel ini mengidentifikasi bagaimana Pendidikan Tinggi Islam mengakselerasi institusi mereka untuk memberi mahasiswa kesempatan belajar agama di luar kelas sehingga mereka memiliki waktu untuk belajar tidak dalam kondisi formal. Data dikumpulkan melalui wawancara mendalam dan pengamatan tidak berpartisipasi. Sekolah Tinggi Agama Islam Negeri Sorong merupakan sumber data utama. Diskusi terarah dilakukan sebagai teknik verifikasi data untuk kepentingan triangulasi. Artikel ini mendiskusikan dua hal utama yaitu perayaan maulid Nabi Muhamamd SAW dan momen Nuzulul Quran. Akhirnya, artikel ini menyimpulkan bahwa institusi pendidikan tinggi memainkan dua peran yaitu pendidikan itu sendiri dan pada saat yang sama mereka menjadi pilar keagamaan bagi masyarakat.
\end{abstract}

Keywords: higher education, religiosity, Islam and education 


\section{Pendahuluan}

Secara nasional, kondisi umat Islam berada dalam suasana kebatinan mayoritas. Hanya saja, beberapa wilayah justru masyarakat muslim berada dalam kondisi minoritas. Tentu sebuah kondisi psikologis yang memberikan pembedaan lingkungan diantara keduanya. Sementara itu, tanggungjawab muslim dimanapun berada sama saja tidak memperhatikan faktor mayoritas atau minoritas (Hendropuspito, 1994: 57-75). Walaupun demikian, tetap saja pengembangan pendidikan Islam menjadi keutamaan masyarakat muslim (Wekke, 2012: 205-226). Dalam kondisi seperti ini, keberadaan Perguruan Tinggi di minoritas muslim menjadi instrumen dalam memperkukuh tradisi masyarakat. Melalui kegiatan di kampus dengan melibatkan peran serta masyarakat akan menjadi sebuah kesinambungan dalam mempertahankan tradisi Islam.

Perguruan Tinggi menjadikan kepemimpinan sebagai bagian utama untuk menggerakkan potensi yang dikelola (Ahmad dkk., 2011: 291-318). Sementara itu, soal akses ke Perguruan Tinggi selalu menjadi masalah di beberapa wilayah (Arar dkk., 2011: 207-228). Sementara kajian tentang tradisi dan pendidikan tinggi baru dalam kajian tentang pelatihan (Hassi, 2012: 1035-1045). Sebagai bagian dari penjaminan mutu, kadang Perguruan Tinggi hanya menggunakan budaya internal untuk dijadikan sebagai pertimbangan pengelolaan (Schomaker, 2015: 149-165). Begitu pula dengan pendidikan tinggi Islam Indonesia, masih semata-mata menggunakan variable keislaman dalam menggerakkan kurikulum (Roslan Mohd Nor dkk., 2014: 261-276). Wilayah Papua Barat dengan keberagaman yang khas menjadi tempat bersemainya kemajemukan (Wekke, 2013: 14).

Kajian pendidikan tinggi masih sebatas pada tema yang berkaitan dengan akses pendidikan (Arar dkk., 2011: 207-228), layanan pendidikan (Brewis, 2013: 119-136), etika (Fantazy \& Abdul Rahim A. Al Athmay, 2014: 180-196), dan akreditasi (Schomaker, 2015: 149-165). Adapun secara khusus tentang minoritas muslim masih sebatas pada pendidikan bahasa (Wekke, 2016: 93-106), etika konsumen (U. Ahmed, Sam Al-Kwifi, Saiti, \& Bin Othman, 2014: 6-23), keseimbangan antara pekerjaan dan keluarga (Sav, Harris, \& Sebar, 2014: 2-18.) dan narasi kolektif (Srour, Sagy, Mana, \& Mjally-Knani, 2013: 231-244). Dengan demikian, kajian pendidikan tinggi dalam konteks lingkungan tertentu belum menjadi pembahasan secara khusus.

Eksistensi umat beragama selalu ditandai dengan adanya tradisi-tradisi keagamaan. Hal ini tidak hanya dalam lingkup besar seperti suatu negara tetapi 
bahkan sampai lingkup yang terkecil yaitu lapisan masyarakat pedesaan. Artikel ini bertujuan untuk mengidentifikasi suasana religius secara praktis dengan melibatkan seluruh sivitas akademika terutama mahasiswanya dalam pelaksanaan tradisi keislaman. Penerapan tradisi keislaman yang penulis paparkan dalam pembahasan berikut lebih spesifik terfokus pada perayaan Nuzul al Quran dan peringatan Maulid Nabi Muhammad SAW. Secara khusus, artikel ini akan membahas tentang tradisi keislaman sebagai bagian dalam membangun spiritual mahasiswa. Aspek minoritas muslim menjadi analisis secara khusus berkaitan dengan kelembagaan Perguruan Tinggi di masyarakat.

\section{Konsepsi Perguruan Tinggi Dalam Tradisi Islam}

Tradisi paling tidak memiliki dua pengertian: pertama, adat kebiasaan turun-temurun (dari nenek moyang) yang masih dijalankan dalam masyarakat; kedua, penilaian atau anggapan bahwa cara-cara yang telah ada merupakan yang paling baik dan benar (Loermans, 2002: 285-294). Dengan demikian, dapat disimpulkan pengertian bahwa tradisi keislaman adalah suatu bentuk tata cara yang sudah turun-temurun dilaksanakan di masyarakat karena dianggap baik dan memiliki nilai-nilai keislaman. Sementara itu Dean menggambarkan tradisi atau budaya sebagai berikut "budaya merupakan suatu proses dinamis dalam penciptaan, penertiban dan pengolahan nilai-nilai insane (Dean, 2014: 20-32). Dalam budaya atau peradaban adalah suatu keseluruhan yang kompleks dari pengetahuan, kepercayaan, seni, moral, hukum, adat-istiadat, serta kemampuan-kemampuan dan kebiasaan lainnya yang diperoleh manusia sebagai anggota masyarakat".

Sedangkan kampus sebagai lingkungan bangunan utama Perguruan Tinggi (universitas, akademi) tempat semua kegiatan belajar mengajar dan administrasi berlangsung (Roslan Mohd Nor dkk., 2014: 261-276). Universitas juga merupakan bentuk kelembagaan yang diartikan Perguruan Tinggi yang terdiri atas sejumlah fakultas yang menyelenggarakan pendidikan ilmiah dan/ atau profesional dalam sejumlah disiplin ilmu tertentu (Ellis dkk., 2007: 9-23). Berdasarkan pemahaman tersebut kiranya dapat diambil pengertian bahwa pelaksanaan tradisi keislaman di universitas adalah pelaksanaan terhadap suatu kebiasaan yang telah menjadi turun-temurun dan biasa dilaksanakan di masyarakat muslim karena dianggap memiliki nilai keislaman yang dilaksanakan oleh kalangan masyakarat akademik atau mahasiswa dilingkungan kampus atau universitas. 
Perguruan Tinggi Islam sebagai bentuk kelembagaan pada jenjang pendidikan tinggi menjadi bagian yang tidak terpisahkan dalam dua hal. Pertama, Perguruan Tinggi, kemudian kedua; kata Islam. Paduan keduanya kemudian membentuk karakteristik tertentu. Diantara karakteristik tersebut adalah; pertama, menekankan pada pencarian, penguasaan dan pengembangan ilmu pengetahuan atas dasar ibadah kepada Allah SWT. Kedua, pencarian tersebut bersifat kesinambungan (long life education), karena menurut konsepnya ilmu pengetahuan dalam Islam itu bukan dibuat, akan tetapi dicari oleh manusia. Sehingga tidak akan berhenti akan tetapi terus berkembang. Ketiga, dalam pencariannya lebih menekankan pada nilai-nilai akhlak (Muhaimin, 2012: 85-97). Dapat dimaknai ilmu pengetahuan itu tidak bebas nilai, akan tetapi bebas dinilai, untuk itu dapat dikritisi dan dinilai dalam kerangka ilmu pengetahuan yang merupakan salah satu ciri dari akhlak yang terpuji, sekaligus tidak hanya pada pengurusan yang bertumpu pada kepentingan ilmu sematamata (Massingham, 2014: 1075-1100). Termasuk adanya perhatian khusus terhadap bahasa Arab (Wekke, 2015: 286-290).

Di masyarakat muslim, pada dasarnya peringatan hari-hari besar Islam tersebut tidak hanya dilaksanakan oleh masyarakat tertentu, melainkan dilaksanakan juga oleh berbagai lapisan masyarakat. Tentunya biaya dan energi dalam penyelenggaraan tersebut tidak bisa dibilang sedikit, namun masyarakat melaksanakannya penuh suka rela dengan harapan pahala dan ridlo dari Allah SWT sebagai berkat dari peringatan tersebut (Nata, 2003: 6890). Untuk itu, penyelenggaraan tradisi keagamaan pada masyarakat muslim dengan mempertimbangkan nilai yang terkandung di dalamnya, Sehingga kadang ditinjau dari segi efek dan dampaknya tidak nampak perubahan secara signifikan dalam hal keintelektualannya. Terutama mengenai pola hidup dalam mengantisipasi akulturasi budaya. Soal ini berkaitan dengan kerelaan untuk mengorbankan harta yang dimiliki demi menyelenggarakan tradisi yang dianggapnya sebagai bagian dari keberagamaan (Sengupta dkk., 2011: 166-183).

Dalam ajaran Islam dapat dinyatakan bahwa Islam telah kuat bila ajarannya telah menjadi tradisi dan membudaya pada masyarakat muslimnya. Sedangkan tradisi dan budaya merupakan bagian yang hidup di masyarakat, sehingga merubah suatu tradisi menjadi hal yang sangat sulit. Dengan demikian adalah suatu keputusan bijak apabila tradisi dan budaya tidak diposisikan berhadapan dengan ajaran, melainkan hanya dijadikan sebagai pintu masuk bagi ajaran yang sesungguhnya (Chafid dkk., 2009: 47-53). Bahkan boleh jadi 
akan terjadi kulturisasi Islam atau sebaliknya yaitu Islamisasi kultur. Karena secara substansi kedua istilah tersebut merupakan sebuah upaya memperkaya khasanah Islamiyah dari segi paradigma Islam.

Pemahaman tentang arti pentingnya al Quran sebagai sumber petunjuk bagi umat manusia yang telah mengajarkan kepada kita bahwa hidup menyendiri secara permanen bagi satu makhluk adalah tidak ada tempat dalam ajaran Islam yang berpedoman pada al Quran. Oleh karena bentuk hidup menyendiri, mandiri dalam tunggal yang mutlak hanyalah sifat Allah SWT semata (Yafie, 1994: 62-70). Dengan demikian pemahaman baik tentang al Quran akan menghadirkan kesadaran pandangan terhadap alam semesta sebagai satu kesatuan. Keterkaitan satu hal, dengan yang lainnya dalam konteks adanya ketergantungan akan kebutuhan dan kepentingan dari yang lainnya. Dari pemahaman yang benar atas petunjuk al Quran maka lahirlah kesadaran akan adanya wujud yang mutlak sebagai penguasa, pengatur dan pemelihara alam yang begitu luas, yaitu Allah SWT.

Sementara, dalam kehidupan masyarakat bahkan sebaliknya tidak sesuai dengan harapan dan makna dari peringatan nuzulul Quran tersebut, pengamalan terhadap ajaran al Quran belum terlaksana dengan baik sebagai bukti pemahaman dan penghayatan terhadap al Quran belum tercapai karena pada praktisnya pelaksanaan tradisi yang telah lama mengakar tersebut berubah sampul menjadi lebih bersifat seremonial. Hal inilah yang menjadi perhatian dengan dilaksanakannya peringatan nuzulul Quran di Perguruan Tinggi sebagai kumpulan manusia-manusia intelektual yang dibina untuk mampu mengaktualisasikan nilai-nilai al Quran dalam kehidupannya. Harapan lebih jauh adalah disamping sebagai ta'kid atau penguat agar tetap eksisnya peringatan tersebut, juga kemampuan berbaur dalam kehidupan nyata di masyarakat juga dapat menjadi tauladan yang baik sebagai cerminan manusia Qurani, yaitu manusia berintelektual tinggi dan berakhlak mulia.

Hal penting yang dapat diambil sebagai hikmah dalam peringatan nuzulul Quran tersebut, diantaranya; pertama, keyakinan penuh bahwa al Quran adalah kitab suci yang tetap terjaga keorisinalannya. Kedua, al Quran adalah solusi terhadap permasalahan yang terjadi pada umat manusia hingga saat ini, baik dari segi politik, ekonomi, budaya, sosial, keagamaan dan sebagainya. Karena apabila ditinjau dari segi sebab hadirnya al Quran adalah tepat saat dunia ini berada dalam goncangan kehancuran diakibatkan bejadnya moral manusia yang merambah ke segala bidang kehidupan pada masanya. Dengan kehadiran al Quranlah sedikit demi sedikit tertata kembali pola kehidupan manusia 
menjadi bernilai. Ketiga, al Quran membawa inti ajaran yang berkenaan dengan akhlaq yang bertumpu pada aqidah dan syariah. Keempat, al Quran memiliki ajaran pokok yang mendasar yaitu tentang pendidikan. Rangkaian lima ayat yang pertama kali turun menggambarkan tentang pendidikan dan aspek-aspeknya, yaitu; pendidikan, murid, kurikulum, peralatan, dan tujuan yang hendak dicapai. Dapat dinyatakan bahwa dalam dunia pendidikan adalah Allah SWT sebagai pendidiknya, Nabi Muhammad SAW sebagai muridnya, kurikulum adalah segala sesuatu yang belum diketahui yang nantinya akan menjadi sumber untuk bahan kajian manusia, peralatan atau sarana adalah pena, dan tujuannya adalah takwa (Nata, 2003). Dengan demikian peringatan nuzulul Quran bagi mahasiswa diharapkan memiliki nilai yang lebih komprehensif ditinjau dari segi kehidupan dalam bermasyarakat, yaitu menjadi tokoh utama dalam perannya sebagai intelektual muslim yang mampu berdampingan dengan tokoh lain di kalangan muslim seperti para kyai, para santri, dan tokoh-tokoh agama yang ada di lingkungan masyarakat. Hal ini dimaksudkan agar mampu memaksimalkan hasil dakwah dalam pengertian yang luas tidak hanya seputar ceramah agama di atas mimbar.

Terdapat beberapa butir sebagai bagian dari hikmah peringatan maulid nabi Muhammad SAW, diantaranya; pertama, tauladan saat beliau masih kanakkanak, kedua, tauladan beliau sebagai seorang suami bagi istrinya, ayah bagi anaknya, dan kakek bagi cucunya, ketiga, tauladan beliau sebagai seorang guru, keempat, tauladan beliau sebagai seorang tokoh bagi masyarakat atau pemerintah terhadap rakyatnya, kelima, tauladan beliau sebagai seorang panglima, ketujuh, tauladan beliau sebagai seorang sahabat, kedelapan, tauladan beliau sebagai seorang pedagang atau pengelola ekonomi, kesembilan, tauladan beliau sebagai seorang hamba, kesepuluh, tauladan beliau sebagai seorang Nabi dan Rasul terhadap umatnya. Masih banyak tauladan-tauladan lain yang dapat dijadikan pedoman dalam berperilaku yang menunjukkan kemuliaan akhlak.

Sebagai seorang Rosul, beliau berdakwah. Perlu dipahami bahwasanya dakwah Islam selalu bersentuhan dengan realitas sosial yang menjadi sasarannya. Dalam perspektif sejarah proses dakwah Islam bila dikaitkan dengan sosio-kultural mendapati dua kemungkinan, yakni; pertama, dakwah Islam mampu memberikan pengaruh terhadap lingkungan sosial, dalam arti mampu memberikan dasar pemikiran secara filosofi terhadap arah pandang dalam proses perubahan masyarakat sehingga terbentuk realitas sosial yang baru. Kedua, dakwah Islam justru dapat dipengaruhi oleh perubahan sosial/ masyarakat, dalam arti penyesuaian model pendekatan agar selalu aktual 
dalam penyampaiannya. Dengan demikian dakwah Islam diartikan sebagai suatu proses yang harus memiliki unsur fleksibilitas, tidak kaku dan mampu menyesuaikan dalam hal penentuan terhadap pemilihan suatu metode.

Dengan demikian, diadakanya peringatan maulid Nabi di Perguruan Tinggi diharapkan para mahasiswa mampu menapak tilas jejak perjuangan Nabi dalam menyiarkan Islam terhadap komunitas yang keras mempertahankan tradisi nenek moyangnya tetapi menjadi luluh dengan metode dakwahnya, yaitu; mau'idzoh hasanah, keteguhan hati, kesabaran dan ketekunan beliau. Sehingga umatnya mau beranjak dari kubangan kesesatan yang tidak disadarinya secara turun-temurun selama berabad-abad lamanya (Tobroni dkk., 1994: 46-50). Wahid mengemukakan bahwa agama dan budaya tidak saling mengalahkan, melainkan berwujud dalam pola nalar keagamaan yang tidak lagi mengambil bentuk otentik dari agama, serta berusaha mempertemukan jembatan yang selama ini melintas antara agama dan budaya (Wahid, 2001: 50-56).

Pada konteks selanjutnya, akan tercipta pola-pola keberagamaan (Islam) sesuai dengan konteks lokalnya dalam wujud "Islam Pribumi" sebagai jawaban dari "Islam otentik" atau "Islam purifikatif" yang ingin melakukan proyek Arabisme di dalam setiap komunitas Islam di seluruh penjuru dunia. "Islam Pribumi” justru memberi keanekaragaman interpretasi dalam praktik kehidupan beragama (Islam) di setiap wilayah yang berbeda-beda. Dengan demikian, Islam tidak lagi dipandang secara tunggal, melainkan beraneka ragam. Tidak ada lagi anggapan Islam yang di Timur Tengah sebagai Islam yang murni dan paling benar, karena Islam sebagai agama mengalami historisitas yang terus berlanjut (Khamami Zada dkk., 2003: 10-16).

Ini dapat dilihat dari praktik ritual dalam budaya populer di Indonesia yang menunjukkan perjumpaan antara Islam dan budaya lokal. Upacara Pangiwahan di Jawa Barat sebagai salah satunya, dimaksudkan agar manusia dapat menjadi wiwoho, yang mulia. Berangkat dari pemahaman ini, masyarakat harus memuliakan kelahiran, perkawinan, dan sebagainya. Semua ritual itu dimaksudkan untuk menunjukkan bahwa kehidupan manusia itu bersifat mulia. Konsep mengenai kemuliaan hidup manusia ini diwarnai oleh kultur Islam yang memandang manusia sebagai makhluk yang mulia (Kuntowijoyo, 1991: 26-30). Sebagai agent of change,ditambah pula dengan bentuk karakteristik pendidikan Islam, mahasiswa diharapkan mampu menginternalisasikan nilainilai Islam yang terkandung dalam al Quran dengan mencontoh pola-pola kehidupan Rasulullah SAW dalam berbagai perannya selain sebagai seorang Utusan atau Rasul. 


\section{Perguruan Tinggi di Minoritas Muslim}

Paparan awal artikel ini menunjukkan bahwa dengan adanya Perguruan Tinggi di lingkungan minoritas muslim dapat menjadi bagian yang menggerakan kesefahaman anara budaya dan agama. Hanya saja, setiap Perguruan Tinggi tentu memiliki kondisi kelembagaan yang berbeda seperti Sekolah Tinggi Agama Islam Negeri (STAIN) Sorong, Sekolah Tinggi Ilmu Tarbiyah YAPIS Manokwari, Papua Barat, Institut Agama Islam Negeri (IAIN) Manado di Sulawesi Utara, Sekolah Tinggi Agama Islam Denpasar, dan Sekolah Tinggi Ilmu Tarbiyah Jembarana, keduanya di Bali. Ketiganya dengan kondisi kelembagaan yang berbeda masing-masing berusaha untuk memberikan perhatian pada bagian dharma pengabdian yang disinergikan dengan dua dharma lainnya. Sementara STAIN Sorong dan IAIN Manado dengan status negeri, sementara STAI Denpasar dengan status swasta. Kedua kategori ini memberikan kekuasaan dan keluasaan keuangan yang berbeda. Masing-masing memiliki tantangan dan pada saat yang sama memberikan peluang yang berbeda. Hanya saja, dengan lingkungan yang mengalami perjumpaan dengan masyarakat non-muslim, maka ada kesempatan untuk memperkuat identitas dengan masyarakat muslim dalam lingkungan yang didiaminya.

Temuan kajian ini menunjukkan pada bagian spiritual, pendidikan tinggi dapat memainkan peran. Sebagaimana dalam kognisi sosial pada orang dewasa, maka pendidikan tinggi Islam memainkan peran dalam pendidikan mahasiswa sebagai pelanggan utama (Sebastian, 2015: 125-131). Termasuk dalam kaitan dengan lingkungan yang didiami untuk memberikan kesempatan dalam memperkaya kemampuan masyarakat (Contessi, 2015: 3-13). Seperti di kawasan Asia Tengah, dimana Perguruan Tinggi menjadi penghubung lintas sektor. Sementara itu, Perguruan Tinggi juga memiliki kesempatan untuk mengembangkan kemampuan sosial bagi masyarakat sekitarnya (Blakemore, 2008: 40-9). Dengan demikian, keberadaan Perguruan Tinggi Islam merupakan bagian masyarakat yang dapat menjadi fasilitator dalam kaitannya dengan pengembangan masyarakat. Termasuk pada pembentukan lingkungan keagamaan (Wekke dkk., 2014: 112-116). Tidak saja berkaitan dengan dharma pengabdian masyarakat tetapi berkaitan pula dengan instrumen pemberdayaan umat.

Pendidikan tinggi merupakan sarana dalam memperkuat keberagamaan. Masing-masing menjadi bagian utama dalam masyarakat yang didiaminya. Sementara lingkungan minoritas justru menjadi tantangan tersendiri. Setiap lembaga berupaya untuk tetap menjalankan fungsi utama pendidikan tinggi. Pada saat yang sama, memiliki kewajiban untuk selalu pula menjadi bagian 
dari dakwah di dalam masyarakat secara internal. Artikel ini menunjukkan bahwa ada fungsi ganda yang diemban Perguruan Tinggi. Mereka berusaha untuk menjalankan kewenangan yang dimandatir sebagai bagian dari lembaga pendidikan tinggi. Pada saat yang sama juga tetap berupaya untuk menjalankan misi keagamaan.

\section{Simpulan}

Esensi pelaksanaan tradisi keislaman pada masyarakat muslim secara umum menjadi perhatian termasuk dalam lingkungan pendidikan tinggi. Hal ini dikarenakan adanya akulturasi budaya terhadap budaya pribumi dengan hilangnya sifat dominan watak asli ketimuran yang telah tergantikan dengan budaya trendi. Kemudian, perayaan lebih bersifat seremonial bukan terhadap penghayatan sejarah atau pemahaman nilai-nilai yang terkandung dalam momentum tersebut bahkan hikmah perayaan sebagai tujuan utama pada awal pembuatan tradisi sudah hampir dapat dipastikan telah hilang. Hanya saja, dengan berbagai upaya, pihak manajemen Perguruan Tinggi juga memberikan penguatan makna pada aktivitas-aktivitas pendidikan yang tidak saja secara formal tetapi juga berkaitan dengan kegiatan yang difomulasi untuk kepentingan aktivitas pendidikan.

Pelaksanaan peringatan maulid dan nuzul al Quran merupakan bagian dari usaha untuk mempertahankan, bahkan merupakan upaya untuk meningkatkan pengetahuan keagamaan mahasiswa. Keduanya akan menjadi sarana untuk menjalankan syi'ar beragama secara internal. Perguruan Tinggi melalui kegiatan-kegiatan keagamaan sebagai langkah untuk melakukan internalisasi ajaran keagamaan yang tidak secara khusus dilaksanakan sebagai kegiatan pendidikan formal, tetapi justru dilaksanakan dalam suasana yang dikemas sedemikian rupa untuk memberikan pengalaman beragama dalam interaksi masyarakat di luar Perguruan Tinggi.

\section{Daftar Pustaka}

Ahmad, K., \& Ogunsola, O. K. 2011. An Empirical Assessment of Islamic Leadership Principles. International Journal of Commerce and Management. Vol. 21, No. 3: 291-318

Arar, K., \& Mustafa, M. 2011. Access to Higher Education for Palestinians in Israel. Education. Business and Society: Contemporary Middle Eastern Issues. Vol. 4, No. 3: 207-228. 
Blakemore, S.J. 2008. Development of The Social Brain During Adolescence. Quarterly Journal of Experimental Psychology. Vol. 61, No. 1: 40-9.

Brewis, G. 2013. Education for Service: Social Service and Higher Education in India and Britain 1905-1919. History of Education Review. Volume 42, Nomor 2: 119-136

Chafid, M. Adnan, dan Asrori, A.Ma'ruf. 2009. Tradisi Islam (Panduan Prosesi Kelahiran,Perkawinan, Kematian). Surabaya: Khalista.

Contessi, N. P. 2015. Central Asia in Asia: Charting Growing Trans-Regional Linkages. Journal of Eurasian Studies. Vol. 7, No. 1:, 3-13.

Dean, J. 2014. Muslim values and market value: a sociological perspective. Journal of Islamic Marketing, 5 November 2012: 20-32

Ellis, R. a., Jarkey, N., Mahony, M. J., Peat, M., \& Sheely, S. 2007. Managing Quality Improvement Of Elearning In A Large, Campus-Based University. Quality Assurance in Education. Vol. 15, No. 1: 9-23.

Fantazy, K., \& Abdul Rahim A. Al Athmay, A.-A. 2014. Ethics And Religion In Higher Education. International Journal of Commerce and Management. Vol. 31, No. 10: 1035-1045

Hassi, A. 2012. Islamic Perspectives on Training and Professional Development. Journal of Management Development. Vol. 31, No. 10: 1035-1045.

Hendropuspito. 1994. Sosiologi Agama. Yogyakarta: Kanisius.

Khamami Zada dkk. 2003. Islam Pribumi: Mencari Wajah Islam Indonesia. Jurnal Tashwirul Afkar. No. 14 . Jakarta: Lakpesdam.

Kuntowijoyo. 1991. Paradigma Islam: Interpretasi untuk Aksi. Bandung: Mizan.

Loermans, J. 2002. Synergizing the Learning Organization and Knowledge Management. Journal of Knowledge Management. Vol. 6, No. 3: 285-294

Massingham, P. 2014. An Evaluation of Knowledge Management Tools: Part 1 - Managing Knowledge Resources. Journal of Knowledge Management. Vol.18, No. 6: 1075-1100

Muhaimin. 2012. Paradigma Pendidikan Islam. Bandung: Remaja Rosda 
Karya.

Nata, Abuddin. 2003. Pendidikan Spiritual Dalam Tradisi Keislaman. Bandung: Angkasa.

Roslan Mohd Nor, M., \& Malim, M. 2014. Revisiting Islamic Education: The Case of Indonesia. Journal for Multicultural Education. Vol. 8 No.4: 261-276.

Sav, A., Harris, N., \& Sebar, B. 2014. Australian Muslim Men Balancing Work, Family And Religion:A Positive Look at A Negative Issue. Personnel Review. Vol. 43, No. 1: 2-18.

Schomaker, R. 2015. Accreditation and Quality Assurance in the Egyptian Higher Education System. Quality Assurance in Education. Vol. 23, No. 2: $149-165$.

Sebastian, C. L. 2015. Social Cognition in Adolescence: Social Rejection and Theory of Mind. Psicología Educativa. Volume 21, Nomor 2: 125-131

Sengupta, J., \& Sarker, D. 2011. Caste and Religious Diversity on Human Capital Outcome: Evidence from India. Humanomics. Vol. 27, No. 3 : 166-183

Srour, A., Sagy, S., Mana, A., \& Mjally Knani, S. 2013. Collective Narratives as Indicators of Examining Intergroup Relations. International Journal of Conflict Management. Vol. 24, No. 3: 231-244. https://doi.org/10.1108/ IJCMA-10-2012-0072.

Tobroni dan Arifin, Syamsul. 1994. Islam Pluralisme Budaya dan Politik. Yogyakarta: SIPRES.

U. Ahmed, Z., Sam Al-Kwifi, O., Saiti, B., \& Bin Othman, N. 2014. Consumer behavior dynamics of Chinese Minorities. Journal of Technology Management in China. Vol. 9, No. 1: 6-23.

Wahid, Abdurrahman. 2001. Pergulatan Negara, Agama, dan Kebudayaan. Jakarta: Desantara.

Wekke, I. S. 2012. Pesantren Dan Pengembangan Kurikulum Kewirausahaan: Kajian Pesantren Roudahtul Khuffadz Sorong Papua Barat. Inferensi. Vol. 6, No. 2: 205-226. 
Wekke, I. S. 2013. Islam Di Papua Barat: Tradisi dan Keberagaman. Ulul Albab Jurnal Studi Islam. Vol. 14, No 2. 156-162.

Wekke, I. S. 2015. Arabic Teaching and Learning: A Model from Indonesian Muslim Minority. Procedia-Social and Behavioral Sciences.

Wekke, I. S., \& Sahlan, A. 2014. Strategy in Creating School Environment: Lessons from High Schools in Indonesia. Procedia-Social and Behavioral Sciences.

Wekke, Ismail Suardi. 2016. Muslim Minority on Learning and Religious Teaching in Manado of North Sulawesi, Indonesia. TAWARIKH: International Journal for Historical Studies. Vol. 8, No. 1: 93-106.

Yafie, Ali. 1994. Menggagas Fiqih Sosial. Bandung: Mizan. 